\title{
Keefektifan Model Pembelajaran Index Card Match terhadap Hasil Belajar Mata Pelajaran IPA
}

\section{Melisa Intan Sari ${ }^{*}$, Rustopo ${ }^{2}$, Ferina Agustini ${ }^{3}$}

1,2,3 Universitas PGRI Semarang, Indonesia

\author{
ARTICLEINFO \\ Article history: \\ Received 18 Desember \\ 2017 \\ Received in revised form \\ 30 Desember 2017 \\ Accepted 15 Januari 2018 \\ Available online 20 \\ Februari 2018 \\ Kata Kunci: \\ Sains, Hasil Belajar, Model \\ Pencocokan Kartu Indeks \\ Keywords: \\ Science, Learning Outcomes, \\ Index Card Match Model
}

\begin{abstract}
A B S T R A K
Masalah ini disebabkan oleh proses belajar yang monoton dan membosankan, siswa kurang antusias dalam proses pembelajaran. Masih menekankan pembelajaran ceramah, siswa merasa bosan dan enggan memperhatikan penjelasan guru dan siswa terlihat pasif. Tujuan dari penelitian ini adalah untuk mengetahui apakah model pencocokan kartu indeks efektif terhadap pembelajaran IPA kelas II SD Negeri 02 Pojok Kabupaten Grobogan. Jenis penelitian ini adalah penelitian kuantitatif. Hasil penelitian terdapat perbedaan hasil belajar siswa setelah menggunakan model indeks kartu korek api dalam kegiatan belajar mengajar yang telah dilakukan. Tampaknya persentase ketuntasan belajar dari $26,92 \%$ naik menjadi $88,46 \%$
\end{abstract}

\section{A B S T R A C T}

This problem is caused by the monotonus and boring learning prosecess, students lack enthusiasm in the learning process. Still emphasizing the lecture learning, students feel bored and reluctant to pay attention to the explanation of the teacher and students looked passive. The purpose of this study was to know whether index card match model effective against to the learning IPA grade II SD Negeri 02 Pojok Kabupaten Grobogan. This type of research is quantitative research. The results of the study that there were differences in result students' learning after using the index card match model in teaching and learning activities that have been done It appears that the percentage of learning completeness from $26,92 \%$ rose to $88,46 \%$ 


\section{Pendahuluan}

Pendidikan merupakan sarana penting untuk meningkatkan kualitas sumber daya manusia (SDM) dalam membangun keberhasilan suatu bangsa. Berdasarkan Undang-Undang nomor 20 Tahun 2003, tentang Sistem pendidikan Nasional Pasal 1 ayat 1 menyebutkan bahwa Pendidikan adalah usaha sadar dan terencana untuk mewujudkan suasana belajar dan proses pembelajaran agar peserta didik secara aktif mengembangkan potensi dirinya untuk memiliki kekuatan spiritual keagamaan, pengendalian diri, kepribadian, kecerdasan, akhlak mulia, serta keterampilan yang diperlukan dirinya, masyarakat, bangsa dan negara.

Menurut Djamarah dan Zain (2013: 44), proses pembelajaran adalah inti dari proses pendidikan. Proses pembelajaran ini sebagai penentu keberhasilan seorang guru mengajar. Pada struktur Kurikulum Tingkat Satuan Pendidikan (KTSP) SD memuat 8 mata pelajaran ditambah muatan lokal, yang diantaranya terdapat mata pelajaran Ilmu Pengetahuan Alam (IPA). Samatowa (2016:1) Ilmu Pengetahuan Alam (IPA) atau sains dalam arti sempit sebagai disiplin ilmu dari physical sciences dan life sciences. Yang termasuk physical sciences adalah ilmu-ilmu astronomi, kimia, geologi, mineralogi, meteorologi, dan fisika. Sedangkan life science meliputi biologi (anatomi, fisiologi, zoologi, citologi, dan seterusnya).

Berdasarkan hasil wawancara dengan guru kelas III di SD Negeri 02 Pojok Kabupaten Grobogan. Menyatakan bahwa pada mata pelajaran IPA masih dibawah Kriteria Ketuntasan Minimal (KKM). KKM yang ditentukan oleh SD Negeri 02 Pojok Kabupaten Grobogan adalah 70 melihat pada Hasil Ulangan Harian pada mata pelajaran IPA masih terdapat 73\% siswa yang belum memenuhi KKM.

Pada saat wawancara juga menemukan berbagai dugaan tentang masalah tersebut, diantaranya hasil belajar pada mata pelajaran IPA siswa yang rendah. Menurut Susanto (2016:5) hasil belajar yaitu perubahan - perubahan yang terjadi pada diri siswa, baik yang menyangkut aspek kognitif, afektif, dan psikomotor sebagai hasil dari kegiatan belajar. Hal ini disebabkan oleh dalam proses pembelajaran masih terkesan monoton dan membosankan, siswa kurang bersemangat dalam proses pembelajaran karena pembelajaran kurang kreatif dan inovatif dalam menciptakan kelas yang menyenangkan karena masih menekankan pada model pembelajaran ceramah, siswa merasa jenuh dan enggan untuk memperhatikan penjelasan dari guru dan siswa terlihat pasif, karena dalam proses pembelajaran kurang melibatkan siswa.

Solusi yang dapat digunakan untuk mengatasi masalah yang dihadapi adalah dengan mengembangkan model pembelajaran yang dapat menciptakan suasana belajar yang aktif, menyenangkan, membantu siswa memahami materi pelajaran yang sulit, dan mengubah cara mengajar agar siswa termotivasi dalam belajar dan terlibat secara aktif saat mengikuti kegiatan proses pembelajaran yaitu menggunakan model pembelajaran Index Card Match.

Menurut Suprijono (2014: 120) mengatakan bahwa model pembelajaran Index Card Match (mencari pasangan kartu) adalah suatu strategi yang cukup menyenangkan digunakan untuk memantapkan pengetahuan siswa terhadap materi yang dipelajari. Dengan menggunakan model pembelajaran ini pembelajaran akan lebih menarik dalam belajar dikelas karena siswa akan mencari pasangan kartu yang sesuai. Sementara menurut Sagita (2018:169) bahwa model Index Card Match adalah siswa dituntut untuk bekerjasama dengan pasangannya. Setiap siswa memperoleh satu kartu berupa kartu soal atau kartu jawaban. Kemudian siswa mencari pasangannya. Temuan ini didukung oleh peneliti Ayuningtyas (2016) mengatakan bahwa model Index Card Match dapat meningkatkan pemahaman konsep matematika dan hasil belajar siswa.

Berdasarkan uraian diatas dan wawancara yang dilakukan oleh peneliti di SD Negeri 02 Pojok Kabupaten Grobogan dilakukan penelitian tentang "Keefektifan Model Pembelajaran Index Card Match Terhadap Hasil Belajar Mata Pelajaran IPA Kelas III SD Negeri 02 Pojok Kabupaten Grobogan".

\section{Metode}

Peneliti melakukan penelitian di SD Negeri 02 Pojok Kabupaten Grobogan pada kelas III. Penelitian ini dilaksanakan pada Semester I Tahun Pelajaran 2018/2019 bulan Juli - Desember dan pengambilan data dilaksanakan pada tanggal 26 - 29 November 2018. Dalam penelitian ini terdapat dua variabel, yaitu variabel bebas dan variabel terikat: Variabel Bebas (X), Variabel bebas adalah variabel yang mempengaruhi atau yang menjadi sebab perubahan. Variabel bebas pada penelitian ini yaitu model pembelajaran Index Card Match. Variabel Terikat (Y), Variabel terikat adalah variabel yang dipengaruhi atau yang menjadi akibat, karena adanya variabel bebas. Variabel terikat pada penelitian ini adalah hasil belajar pada mata pelajaran IPA siswa kelas III SD N 02 Pojok Kabupaten Grobogan.

Metode penelitian pada dasarnya adalah cara ilmiah untuk mendapatkan data dengan tujuan dan keadaan tertentu Sugiyono (2015:2). Pada penelitian ini merupakan penelitian kuantitatif. Desain 
penelitian yang digunakan dalam penelitian ini adalah pre-experimental design dengan bentuk one-group pretest-posttest design.

Populasi dalam penelitian ini adalah keseluruhan siswa kelas III SD N 02 Pojok Kabupaten Grobogan. Menurut Sugiyono (2015:81) sampel adalah bagian dari jumlah dan karakteristik yang dimiliki oleh populasi tersebut. Sampel dalam penelitian ini adalah siswa kelas III yang berjumlah 26 yang terdiri dari laki - laki 12 dan perempuan 14 siswa. Teknik sampling yang digunakan dalam penelitian ini adalah Nonprobability sampling. Nonprobability sampling adalah teknik pengambilan sampel yang tidak memberi peluang atau kesempatan sama bagi setiap unsur atau anggota populasi untuk dipilih menjadi sampel.

Teknik pengumpulan data menggunakan nontes diantaranya wawancara dan dokumentasi. Dalam peneliti melibatkan diri dalam situasi subjek yang diteliti sebelum dan selama dilaksanakan pembelajaran menggunakan dokumentasi dan tes tertulis. Instrumen penelitian berupa lembar wawancara, dokumentasi berupa foto kegiatan pembelajaran, tes meliputi bentuk tes, metode penyusunan tes, uji instrumen tes (validitas, reliabilitas, taraf kesukaran, daya pembeda).

Teknik analisis data berupa analisis data adapun rumus yang digunakan uji normalitas awal (pretest) dan uji normalitas akhir (posttest). Kemudian menggunakan rumus uji t atau uji hipotesis selanjutnya uji ketuntasan belajar berupa uji ketuntasan belajar individual dan uji ketuntasan belajar klasikal. Dengan kriteria siswa telah menguasai sekurang-kurangnya $70 \%$ terhadap materi setiap bahasan yang diajukan. Ketuntasan individu dan klasikal $\geq 70$ tuntas.

\section{Hasil dan Pembahasan}

Dari hasil penelitian yang dilakukan oleh peneliti selama melakukan penelitian maka diperoleh data hasil belajar siswa dalam ranah kognitif (pengetahuan) yaitu nilai pretest dan posttest sebagai berikut:

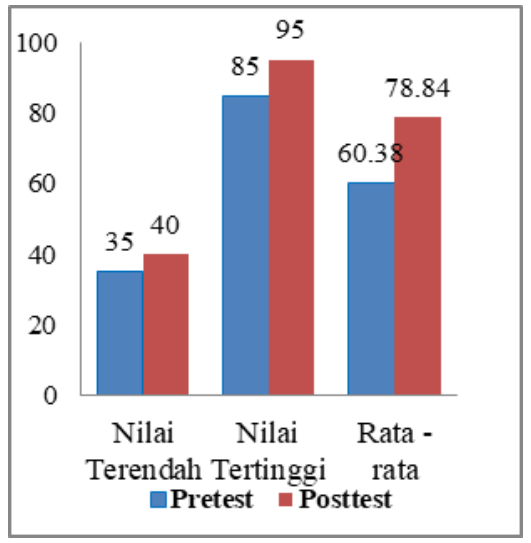

Gambar 1. Nilai Terendah, Tertinggi dan Rata-rata Pretest-Posttest

Berdasarkan Gambar 1 dapat diketahui bahwa nilai rata - rata siswa sebelum diberikan perlakuan sebesar 60,38 dan nilai rata - rata siswa sesudah diberi berlakuan sebesar 78,84. Setelah diberi perlakuan dengan model pembelajaran index card match nilai rata- rata hasil belajar siswa mengalami peningkatan sebesar 18,46.

Uji Analisis Persyaratan Data , Analisis Uji Normalitas Awal ,Uji normalitas awal digunakan untuk mengetahui apakah hasil awal (pretest) berdistribusi normal atau tidak.

Tabel 1. Hasil Uji Normalitas Awal

\begin{tabular}{llll}
\hline Kelas & & $\mathrm{L}_{0}$ & Keterangan \\
\hline Responden & 26 & 0,1015 & Distribusi Normal \\
\hline & & Sumber: Data Hasil Penelitian
\end{tabular}

Berdasarkan Tabel 1 hasil uji nomalitas awal (pretest) setelah mencari harga Ltabel dari nilai kritis uji liliefors dengan taraf signifikan $\alpha=5 \%$ dan $n=26$ diperoleh Ltabel $=0,173$. Sehingga dapat disimpulkan bahwa $L 0<$ Ltabel yaitu: 0,1015 $<0,173$ maka $\mathrm{H}_{0}$ diterima. Hasil uji normalitas menunjukkan bahwa data pretest siswa berasal dari populasi yang berdistribusi normal. 
Analisis Uji Normalitas Akhir, Uji normalitas akhir digunakan untuk mengetahui apakah hasil akhir (posttest) berdistribusi normal atau tidak.

Tabel 2. Hasil Uji Normalitas Akhir

\begin{tabular}{lllll}
\hline Responden & $t_{\text {hitung }}$ & $t_{\text {tabel }}$ & & Ket \\
26 & & & \\
& 11,0455 & 1,708 & $\mathrm{H}_{0}$ ditolak \\
& & & $\mathrm{H}_{\mathrm{a}}$ diterima \\
\hline
\end{tabular}

Sumber: Data Hasil Penelitian

Berdasarkan Tabel 2 hasil uji nomalitas awal (pretest) setelah mencari harga Ltabel dari nilai kritis uji liliefors dengan taraf signifikan $\alpha=5 \%$ dan $n=26$ diperoleh Ltabel $=0,173$. Sehingga dapat disimpulkan bahwa $L 0<$ Ltabel yaitu: 0, $1275<0,173$ maka $\mathrm{H}_{0}$ diterima. Hasil uji normalitas menunjukkan bahwa data pretest siswa berasal dari populasi yang berdistribusi normal.

Tabel 3. Uji t

\begin{tabular}{llll}
\hline Kelas & $\mathrm{N}$ & $\mathrm{L}_{0}$ & Ket \\
Responden & 26 & 0,1275 & Distribusi normal. \\
\hline
\end{tabular}

Uji Hipotesis (Uji t)

Berdasarkan Tabel 3 Setelah menerapkan model pembelajaran index card match data nilai pretest dan posttest dianalisis uji-t bahwa berdasarkan uji-t terdapat perbedaan yang signifikan terhadap hasil belajar siswa kelas III pada mata pelajaran IPA dalam kegiatan belajar. Hal ini dibuktikan dengan perhitungan uji-t hasil $t_{\text {hitung }}$ sebesar 11,0455 dengan distribusi uji $\mathrm{t}$ diperoleh $\mathrm{db}=\mathrm{n}-1=26-1=25$ dengan taraf signifikan $5 \%$ di dapatkan $t_{\text {tabel }}$ sebesar 1,708 sehingga $t_{\text {hitung }}>t_{\text {tabel }}$ atau 11,0455 $>1,708$ yang artinya $\mathrm{H}_{0}$ ditolak dan $\mathrm{H}_{\mathrm{a}}$ diterima. Perhitungan tersebut menunjukan bahwa terdapat perbedaan pada hasil belajar siswa setelah menggunakan model pembelajaran index card match dalam kegiatan pembelajaran yang telah dilakukan. Sehingga dapat disimpulkan bahwa pembelajaran dengan menggunakan model pembelajaran index card match efektif terhadap hasil belajar siswa dalam ranah kognitif (pengetahuan).

\section{Uji Ketuntasan Belajar}

Dari perhitungan ketuntasan belajar klasikal diperoleh 26,92\% dari jumlah keseluruhan. Sedangkan perhitungan ketuntasan belajar klasikal pada posttest bahwa jumlah siswa 26 siswa yang mengikuti tes dan sebanyak 23 siswa yang mencapai ketuntasan belajar sesuai nilai KKM. Dan sebanyak 3 siswa yang belum dapat mencapai ketuntasan belajar sesuai nilai KKM. Dari perhitungan diatas yang menggunakan rumus ketuntasan belajar klasikal diperoleh 88,46\% dari jumlah keseluruhan.

\section{Simpulan dan Saran}

Berdasarkan hasil penelitian yang dilakukan pada kelas III di SD Negeri 02 Pojok Kecamatan Tawangharjo Kabupaten Grobogan, maka dapat disimpulkan bahwa model pembelajaran index card match efektif digunakan untuk meningkatkan hasil belajar mata pelajaran IPA siswa kelas III SD Negeri 02 Pojok Kabupaten Grobogan. Hal tersebut dibuktikan dengan hasil ketuntasan belajar klasikal ranah kognitif pada pretest $26,92 \%$ dan posttest $88,46 \%$. Selain itu dibuktikan dengan hasil hipotesis melalui uji paired samples $t$-test dimana $t_{\text {hitung }}>t_{\text {tabel }}$ berdasarkan hasil analisis tersebut di peroleh $t_{\text {hitung }}>t_{\text {tabel }}$ atau 11,0455 > 1,708, maka $\mathrm{H}_{0}$ ditolak dan $\mathrm{H}_{\mathrm{a}}$ diterima. Artinya, bahwa model pembelajaran index card match efektif terhadap hasil belajar siswa dalam ranah kognitif (pengetahuan) kelas III SD Negeri 02 Kabupaten Grobogan. (1) Dengan menggunakan model pembelajaran index card match dalam proses pembelajaran sebagai model pembelajaran yang menarik dan mampu meningkatkan hasil belajar siswa. (2) Siswa diharapkan untuk bisa berpartisipasi secara aktif agar tujuan pembelajaran tercapai secara optimal. (3) Penelitian ini diharapkan bermanfaat untuk memberikan konstribusi bagi sekolah dalam mengembangkan model pembelajaran yang lebih bervariasi dan kreatif. 


\section{Daftar Rujukan}

Arikunto, Suharsimi. 2016. Dasar - Dasar Evaluasi Pendidikan. Jakarta: PT Bumi Aksara.

Arikunto, Suharsimi. 2013. Prosedur Penelitian Suatu Pendekatan Praktik. Jakarta: Rineka Cipta.

Djamarah, Syaiful Bahridan Azwan Zain. 2013. Strategi Belajar Mengajar. Jakarta: Rineka Cipta.

Farahwati, Ayuningtyas. 2016." Pengaruh Model Pembelajaran Index Card Match (Icm) Terhadap Hasil Matematika Pada Siswa Kelas V Sd N 2 Cepokomulyo Kendal". Skripsi. Semarang: Universitas PGRI Semarang.

Nafi'ah, Siti Anisatun. 2018. Model - Model Pembelajaran Bahasa Indonesia di SD/MI. Yogyakarta: Ar-Ruzz Media.

Sadiman,dkk. 1990. Media Pendidikan : Pengertian, Pengembangan dan Pemanfaatannya. Jakarta : CV. Rajawali Ilmu.

Shaodih Sukmadinata, Nana. 2007. Pengembangan Kurikilum : Teori dan praktik. Bandung : PT. Remaja Rosdakarya

Samatowa, Usman. 2016. Pembelajaran IPA di Sekolah Dasar. Jakarta: Indeks.

Sagita, Isabela Ine, Dkk. 2018. "Pengaruh Metode Kooperatif Index Card Match Dalam Pembelajaran Sejarah Terhadap Hasil Belajar Siswa Kelas X-IIS Di SMA Negeri 16 Surabaya”. e-jurnal Pendidikan Sejarah, Vol $\quad 6 \quad$ No 1. 2018.http://jurnalmahasiswa.unesa.ac.id/index.php/avatara/article/view/22515/20506. Diakses 05 Juni 2018

Soegeng Ysh, A.Y. 2016. Dasar - Dasar Penelitian. Semarang: IKIP PGRI Press.

Suprijono, Agus. 2014. Cooperative Learning Teori \& Aplikasi PAIKEM. Yogyakarta: Pustaka Pelajar.

Sugiyono. 2015. Metode Penelitian Pendidikan Pendekatan Kuantitatif, Kualitatif, dan $R \&$ \& . Bandung: Alfabeta.

Susanto, Ahmad. 2016. Teori Belajar \& Pembelajaran di Sekolah Dasar. Jakarta: Kencana Prenada Media Grup.

Undang-undang Republik Indonesia Nomor 20 Tahun 2003 tentang Sistem Pendidikan Nasional. 2003. Jakarta: Sekertaris Negara Republik Indonesia.

Trianto. 2007. Model-Model Pembelajaran Inovatif Berorientasi Konstroktivistik: Konsep, Landasan TeoritisPraktis dan Implementasinya. Jakarta: Prestasi Pustaka

Yamin, Martinis. 2007. Profesionalisasi Guru dan Inplementasi KTSP. Jakarta : Gedung Persada Press

Zaini, Hisyam dkk. 2007. Strategi Pembelajaran Aktif. Yogyakarta : CTSD . 